\title{
Determining the Operating Temperature of Solar Panels on Vehicles
}

\author{
Aaron Wheeler ${ }^{1}$, Michael Leveille ${ }^{1}$, Ignacio Anton ${ }^{1,2}$, Ashling Leilaeioun ${ }^{1}$, and Sarah Kurtz ${ }^{1}$ \\ ${ }^{1}$ University of California Merced, Merced, CA, 95340; USA, ${ }^{2}$ Universidad Politécnica de Madrid, Spain
}

\begin{abstract}
A technical basis for measurement of the operating temperatures of PV modules in vehicle-integrated applications is explored. Convective and radiative heat transfer are modeled to elucidate the methodology. Data reported for sister modules mounted in an experimental black box and in the sun roof of a car show very similar temperatures. The box provides a uniform environment in the closed configuration, but can be adjusted to explore a wider range of operating environments by opening or closing the sides and by insulating the back.
\end{abstract}

\section{INTRODUCTION}

As automobile manufacturers explore implementation of solar panels, they benefit from standard methods for comparing different solar panel designs. The International Electrotechnical Commission (IEC) is exploring development of such standards including the effects of a curved surface, modeling of irradiance on the car roof and effects of partial shade [1]. One piece of characterizing modules for vehicle-integration is to define a methodology for measuring module operating temperature, which is expected to be higher than in an open-rack configuration and is a key element of defining the performance of the solar panels. Roof-mounted modules have been reported to experience roughly twice the temperature rise (over ambient) of a module mounted on an open rack [2-5].

While measuring the operating temperature of a vehiclemounted module is relatively straightforward, possible operating configurations may be highly variable. The ability to test candidate solar panels in a standardized way, without the need to integrate each candidate into a car, would benefit vehicle manufacturers, researchers, and PV module manufacturers alike.

Ultimately, vehicle owners would like to understand the energy that will be supplied by the solar panel. Energy output depends not only on the meteorological conditions, but also on the vehicle's situation. Situations can include low/medium/high speed driving, whether the inside of the vehicle is climate controlled, and the transmission of sunlight into the interior of the vehicle. Such detailed modeling will be critical to quantifying and optimizing the value of the solar panels for vehicles.

The IEC has addressed the challenge of modeling energy yield for flat-plate modules in IEC 61853 by measuring the performance under a matrix of conditions, then fitting the data to Eq. 1:

$$
\left(T_{m o d}-T_{a m b}\right)=G /\left(u_{0}+u_{1} v\right)
$$

where $T_{\text {mod }}, T_{a m b}, G$, and $v$ are the measured module temperature, ambient temperature, irradiance, and wind speed, respectively, and $u_{0}+u_{1}$ are fit variables describing the effects of irradiance and wind speed, respectively. The standard describes data filtering, adjustment of the data using a reference module mounted on either side, and mounting guide lines for open-rack testing, noting "In the case of modules not designed for open-rack mounting, the test module(s) shall be mounted as recommended by the manufacturer" [6]. The fit coefficients are then used to calculate the operating temperature under the standard reporting conditions, resulting in the Nominal Module Operating Temperature (NMOT).

Our goal is to provide a technical basis for a test that can be easily executed at any test lab and that provides the information a vehicle manufacturer would like in assessing the operating temperature of a module integrated into a car roof. The paper uses a simple model to characterize the heat transfer and presents data to compare the temperatures of modules mounted in a black box with those mounted in the sunroof of a car. The effects of modifying the design of the box are also explored. Example data are evaluated to compare the operating temperatures of $\mathrm{Si}$ and GaAs modules.

\section{METHODOLOGY}

\section{A. Definition of operating temperature}

IEC 61215 (2005 edition) [5] defined Nominal Operating Cell Temperature (NOCT) as the standard metric for module operating temperature. In short, NOCT is the cell operating temperature at $800 \mathrm{~W} / \mathrm{m}^{2}$ irradiance, $20^{\circ} \mathrm{C}$ ambient temperature and $1 \mathrm{~m} / \mathrm{s}$ wind speed. It is determined by recording the temperature of a cell in the module, $T_{\text {cell }}$, and the ambient temperature, $T_{a m b}$, over a range of irradiance values during times when the wind does not gust over $4 \mathrm{~m} / \mathrm{s}$. Measurement of the cell temperature can require cutting into the module or making a special module with a thermocouple embedded inside. The difference between the cell and ambient temperatures is plotted versus irradiance and a fit line identifies the temperature difference at $800 \mathrm{~W} / \mathrm{m}^{2}$ irradiance. The $N O C T$ value is calculated from Eq. 2, by using the temperature difference for $800 \mathrm{~W} / \mathrm{m}^{2}$ irradiance and applying a correction factor, Factor, based on the average temperature and wind speed observed during the test. [7-8]

$$
\text { NOCT }=\left(T_{\text {cell }}-T_{a m b}\right)+20^{\circ} \mathrm{C}+\text { Factor }
$$

However, in 2016, IEC 61215 was extensively modified and now uses NMOT with two key differences from NOCT: measurement of the back-of-module temperature instead of the cell temperature, and measurement while the module is under load [9]. Both of these changes are expected to result in lower 
values for NMOT relative to NOCT. King, et al, found a $3^{\circ} \mathrm{C}$ difference between the back-of-module temperature and the cell temperature for operation in an open-rack configuration [2]. The effect of removing $15 \%$ to $20 \%$ of the energy by driving an external load rather than operating at open-circuit voltage can be estimated to decrease the temperature by an additional $3-5^{\circ} \mathrm{C}$. Therefore, to reflect the systematically lower values we expect, when comparing the two, we have subtracted $6^{\circ} \mathrm{C}$ from the NOCT to obtain the comparable NMOT for a silicon module in open-rack configuration. We anticipate that the difference between NMOT and NOCT will differ for other configurations and technologies.

\section{$B$. Analyzing the vehicle-integrated PV environment}

The many possible configurations for $\mathrm{PV}$ integration into cars complicates the measurement of operating temperatures because there are so many possible operating configurations. We strive to make new measurements that will both differentiate technologies and be predictive of electricity production. Table I summarizes some considerations. During high-speed driving, we anticipate that the air movement cools the module. The air flow profile and its effect on the module depend more on the shape of the car (which determines the turbulence) and less on the type of PV module. Therefore, this configuration is of lower priority in evaluating PV technologies and was, therefore, not prioritized in this study, as indicated by the "-_" in the last column of Table I. On the other hand, when a car is parked indoors, in the shade or in the dark, we anticipate that the electricity generation will be relatively unimportant. Thus, even if two PV modules perform differently under such conditions, it doesn't affect the total electricity generation.

\section{TABLE I}

Summary of variables guiding prioritization $(+, 0,-)$

\begin{tabular}{|c|c|c|c|}
\hline & & energy & technology \\
\hline \multirow{5}{*}{$\begin{array}{c}\text { Car } \\
\text { operation }\end{array}$} & High speed & 0 & - \\
\hline & Low speed & 0 & + \\
\hline & Stopped & 0 & + \\
\hline & Parked in sun & + & + \\
\hline & Parked inside & - & - \\
\hline \multirow{2}{*}{$\begin{array}{c}\mathrm{PV} \\
\text { mounting }\end{array}$} & \multicolumn{3}{|c|}{ Tilt affects convection } \\
\hline & \multicolumn{3}{|c|}{ Insulation affects heat transfer to back } \\
\hline \multirow{3}{*}{$\begin{array}{c}\text { Car } \\
\text { attributions }\end{array}$} & \multicolumn{3}{|c|}{ Open windows } \\
\hline & \multicolumn{3}{|c|}{ Window shades } \\
\hline & \multicolumn{3}{|c|}{ Color of exterior and interior } \\
\hline
\end{tabular}

Table I differentiates three key categories to consider: a) the car's operating mode (high speed vs parked), b) the PV mounting configuration (e.g. insulated or tilt angle), and c) the car's configuration (e.g. number and transparency of windows and color of both the exterior and interior of the car.)

The common theme for most of the parked-car conditions described in Table I is that the module is mounted on a surface that is likely to be hot. Any car parked in the sun is likely to become hot inside. A key question is how this will affect the temperature of the module mounted on the hot car. Thus, of the many questions that could be tackled in this study, we chose to consider the configuration in which a module is mounted on a car that is getting hot because of being parked in the sun. We note that there are many other configurations that are also important to study, so touch upon some of them, as well.

\section{Modeling heat flows for multiple configurations}

There are three mechanisms of heat flow when considering module temperature: conduction, convection, and radiation (Fig. 1a). Muller, et al, showed how a simple model to quantify the radiative and convective heat transfer can be effective at simulating open-rack module temperatures [8]. For simplicity, we neglect conduction through mounting points of the module to the rack. These affect mostly the temperatures near the mounting points for open-rack configurations, but could become more important in vehicle integration.

(a)

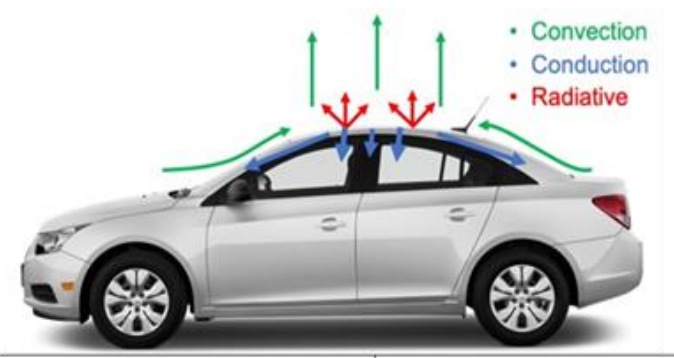

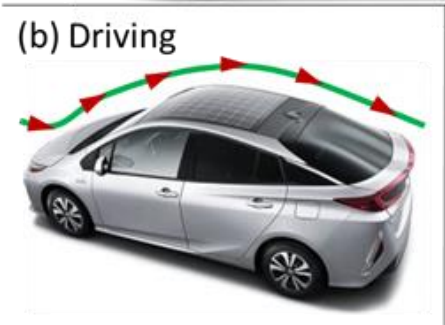

(d) Sunroof Integrated

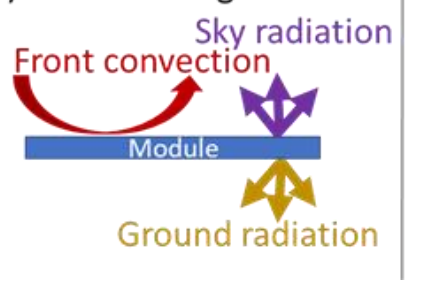

Fig. 1. Convective, conductive, and radiative heat transfer mechanisms depicted for a vehicle-integrated PV module, (a), and schematics of a range of conditions: (b) a car driven at high speed, (c) a PV module in open-rack configuration, (d) a module mounted in a sun roof, and (e) a module mounted on a car with a well-insulated roof/headliner. 


$$
\alpha G=\underbrace{\sqrt[3]{h_{\text {force }}^{3}+h_{\text {free }}^{3}}\left(T_{\text {mod }}-T_{\text {amb }}\right)}_{\text {front convection }}+\underbrace{h_{b}\left(T_{\text {mod }}-T_{b}\right)}_{\text {rear convection }}+\underbrace{\varepsilon_{\text {glass }} \sigma\left(T_{\text {mod }}^{4}-T_{\text {sky }}^{4}\right)}_{\text {front radiation }}+\underbrace{\varepsilon_{b} \sigma\left(T_{\text {mod }}^{4}-T_{g}^{4}\right)}_{\text {rear radiation }}+\underbrace{\eta G}_{\text {electricity }}
$$

TABLE II

COEFFICIENTS FOR APPLICATION OF EQUATION 2 TO THREE CONFIGURATIONS, INCLUDING AN EMPIRICAL MODEL FOR THE BOX

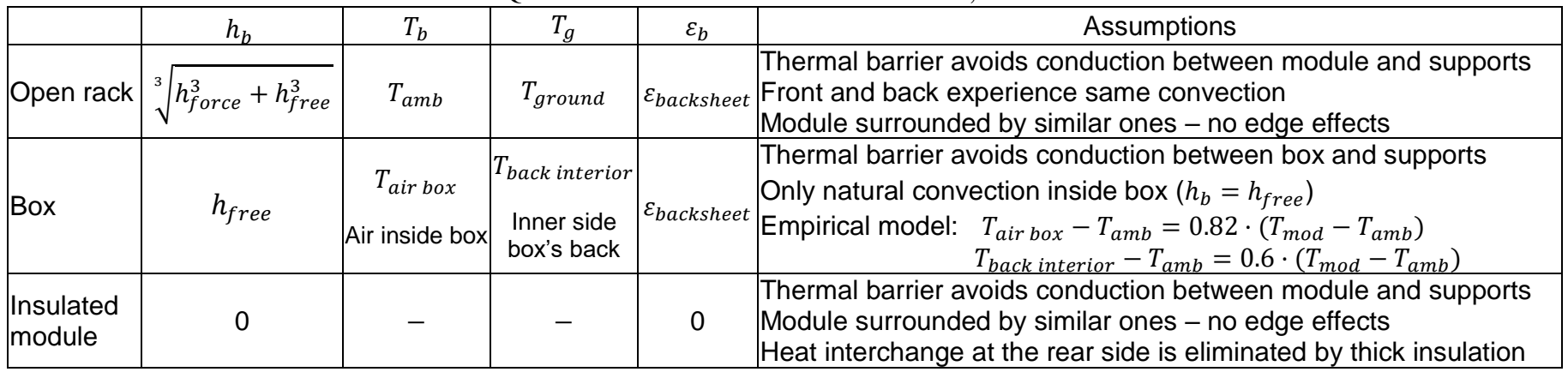

The expected heat flows of common PV configurations are summarized in Figs. 1b-1e. Application of Muller's simple model to a common open-rack configuration shows that about half of the heat is exhausted from the front surface and half from the back surface (Fig. 1c) with both radiative and convective terms being significant (Fig. 2). If a module is insulated on the back (Fig. 1e), the insulation restricts both radiative and convective heat transfer to occur only out of the front of the module (Fig. 2), effectively doubling the temperature rise over ambient.

If a module is mounted in a sun roof with no insulation layer, heat may be radiated from the back of the module into the interior of the vehicle. This mounting scheme requires a slight modification of Muller's model as described in Eq. 3 and Table II.

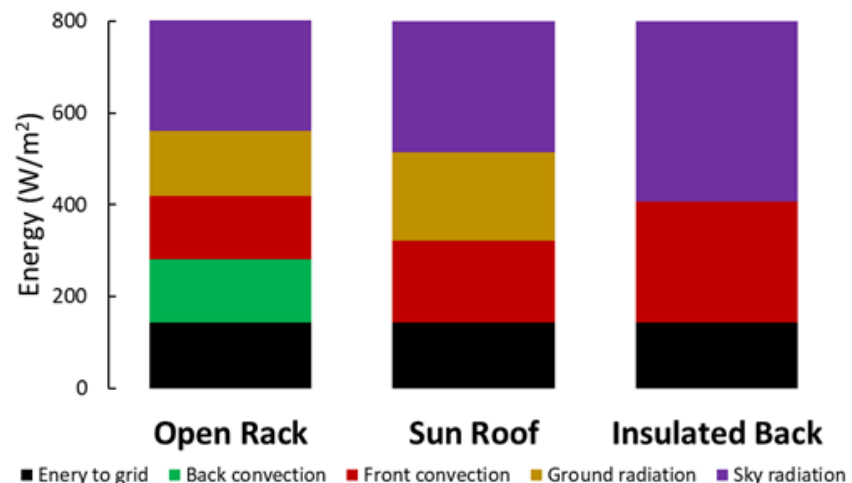

Fig. 2. Partitioning of heat transfer mechanisms in open rack, sunroof mount, and insulated back configurations depicted in Fig. 1 parts $\mathrm{c}, \mathrm{d}$, and e when one $18 \%$ efficient module is under $800 \mathrm{~W} / \mathrm{m}^{2}$ irradiance using the baseline conditions detailed in Table III. (see Eq. 3 and Table II).

Radiation to the sky is the largest form of heat transfer under many conditions, as shown in Fig. 2. For insulated-back mounting, the heat transfer at the back is eliminated. Thus, a steady-state temperature is achieved by increasing the transfer of heat out of the front (this is done by roughly doubling the temperature of the module).

\section{Measurement methods}

Our goal is a test method for acquiring coefficients, and, therefore, operating temperature, representative of a vehicleintegrated module without actually having to mount each module in a vehicle. Based on the existing literature for openrack and insulated-back mounting configurations, we refer to that literature for the extremes and focus our test design on modules mounted on hot surfaces.

A black box was constructed using guidance from ASTM G7M-13 [10] and was designed to hold multiple modules of different sizes (Fig. 3). In this black box the modules lie in a single plane, simplifying comparisons between modules. Effects of complex curvatures seen in actual car roofs are being studied [1] and are beyond the scope of this work. The box structure and instrumentation are tilted by $5^{\circ}$ (facing south) to avoid accumulation of rain water. Care was taken to reduce conductive cooling effects between the module frames, the internal and external support structures, and the front surface paneling. The test stand is elevated by 1 meter to reduce effects that the ground may have on wind and temperature. The box is designed to operate in two configurations: closed (Fig. 3a) and open (Fig. 3b). The open configuration is meant to approximate an open rack environment for comparison with datasheet STC performance parameters. The closed configuration creates a temperature profile similar to what is observed in cars. 


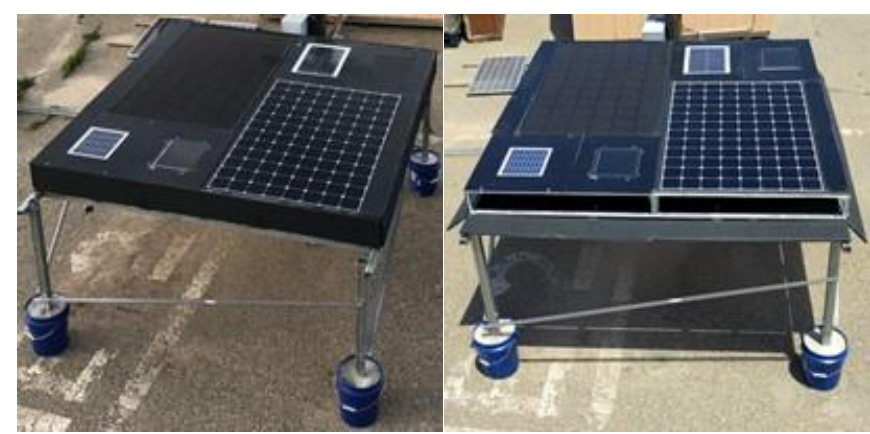

Fig. 3. Black box for testing modules. Details include: dimensions $8 \times 8 \times 0.75$-ft, $5^{\circ}$ tilt, $\mathrm{Al}$ frame, $1 / 16$-in. black anodized aluminum front faces, rear surface and side walls constructed of 5/8-in plywood painted black. Insulating washers are used to thermally isolate module frames from box at mounting contact. Box elevated to 1 meter on posts. (a) with sidewalls closed. (b) with sidewalls open.

Six modules were chosen for study including two monocrystalline modules, two multi-crystalline modules and two gallium arsenide modules. These modules have been described in detail elsewhere in these proceedings [11].

Data were collected every 3 minutes using an MT5 multitracer. Wind speed and direction were recorded using a cup anemometer. Irradiance was obtained from both a thermopile pyranometer and silicon reference cell mounted in-plane with the modules. Temperature readings for back-of-module, box interior, and car locations were obtained using T-type thermocouples. During the entire measurement period the modules operated at maximum power.

While taking data, and evaluating the results, it is useful to understand the variables that need to be controlled. Simulations for NMOT under a range of conditions (after Muller's treatment [8]) are summarized in Table III, showing the impact of the measuring conditions, particularly the influence of sky and ground temperatures. Interestingly, the model shows that NMOT measured on a hot day is lower than if measured on a cold day. This is because the radiative cooling increases with the fourth power of the temperature, suggesting that a module is more effective in cooling itself on a hot day, so the analysis reflects that by calculating a lower NMOT.

\section{TABLE III}

Modeled NMOT under a range of environmental conditions

\begin{tabular}{l|c|c|c} 
CONDITIONS & $\begin{array}{c}\text { OPEN } \\
\text { RACK }\end{array}$ & $\begin{array}{c}\text { BLACK } \\
\text { BOX }\end{array}$ & $\begin{array}{c}\text { INSULATED } \\
\text { BACK }\end{array}$ \\
\hline$\left(T_{S K Y}\left[{ }^{\circ} \mathrm{C}\right], T_{\text {GROUND }}\left[{ }^{\circ} \mathrm{C}\right], T_{A M B}\left[{ }^{\circ} \mathrm{C}\right]\right.$, & $\begin{array}{c}\text { NMOT } \\
{\left[{ }^{\circ} \mathrm{C}\right]}\end{array}$ & $\begin{array}{c}\text { NMOT } \\
{\left[{ }^{\circ} \mathrm{C}\right]}\end{array}$ & $\begin{array}{c}\text { NMOT } \\
{\left[{ }^{\circ} \mathrm{C}\right]}\end{array}$ \\
\hline IIND $[\mathrm{m} / \mathrm{s}])$ & 43.6 & 55.2 & 65.5 \\
BASELINE (-5,20,20,1) & 38.8 & 45.3 & 56.6 \\
COLD SKY (-43,20,20,1) & 46.5 & 55.3 & 70.7 \\
HOT SKY (12,20,20,1) & 41.4 & 57.5 & 56.8 \\
HOT DAY (-5,45,35,1) & 48.3 & 45.5 & 73.9 \\
COLD DAY (-5,5,5,1) & 44.9 & 52.6 & 67.6 \\
LOW WIND (-5,20,20,0.25) & 41.8 & 49.9 & 62.2 \\
HIGH WIND (-5,20,20,1.75) & 41.8
\end{tabular}

Discarding the wind effect (NMOT fixes wind condition at $1 \mathrm{~m} / \mathrm{s}$ ) the main factor causing the variability in NMOT is the temperature difference between ambient and sky, which determines the effectiveness of the front radiation. This effect is more important in the cases of the black box and insulated module, since the heat interchange occurs mainly in the front surface. It is noticeable that the standards do not restrict the skyambient temperature variations, which has been identified as a source of variability for the rated NMOT values [8]. For the case of Merced (CA), where the box is installed, the skyambient variability throughout the year leads to an NMOT variability of $\pm 2.9^{\circ} \mathrm{C}$, but discarding the winter cold days, the variability can be limited to $\pm 1.5{ }^{\circ} \mathrm{C}$ just discarding three months per year.

\section{E. Data analysis}

NMOT as described in IEC 61215 (2016 Edition) and IEC 61853-2 makes use of Eq. 1 to characterize different solar modules. A similar approach by King et al. [2] uses Eq. 4 to compare not only open-rack modules but modules in different configurations and constructions. Here $a$ and $b$ are empirically determined coefficients describing the effect of irradiance and wind speed respectively. According to Koehl et al., these coefficients are less variable for different test sites and conditions than $u_{0}$ and $u_{1}$ [12]. Furthermore, NMOT can be obtained once a module's $a$ and $b$ coefficients are determined.

$$
\left(T_{\text {mod }}-T_{a m b}\right)=G e^{(a+b v)}
$$

When applying either equation (1) or (4), sunny clear days were selected so as to minimize variability of conditions. For analysis to Eq. 4, data were not filtered for wind speed; for fitting to Eq. 1, data were filtered to include only wind speeds between 0.75 and $1.25 \mathrm{~m} / \mathrm{s}$. Since the box has a significant mass, it has a time constant of minutes, so special attention must be devoted to avoid thermal transients, particularly at the beginning of the day.

\section{RESULTS}

\section{A. Comparison of black-box and sun-roof temperatures}

Temperatures of two identical modules deployed concurrently in a car sunroof and in the box are compared in Fig. 4. The car, parked in the test field near the box and monitored by the MT5, had a foam headliner installed beneath the module creating a chamber a few centimeters thick. Air temperatures of this chamber and vehicle cabin were observed to be higher than the back-of-module temperature indicating heat flow into the back of the module. The temperature profile of the module in the black box followed closely that of the module integrated into the car sunroof. 


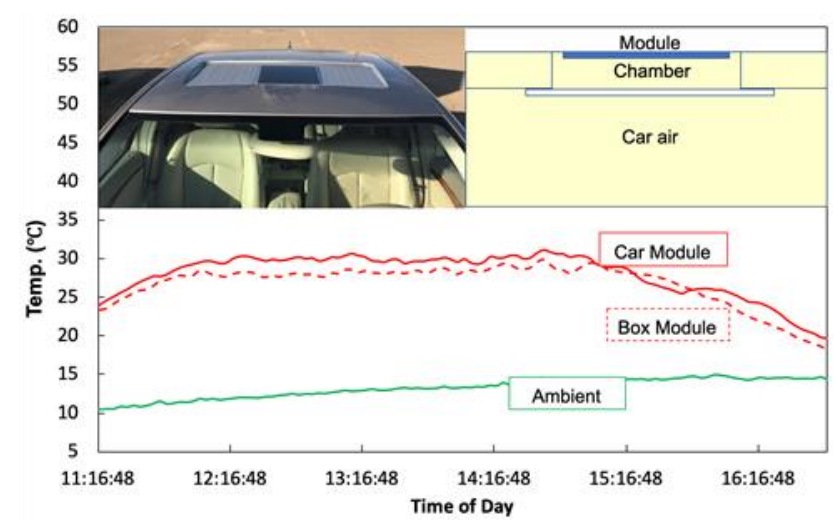

Fig. 4. Temperatures of sister modules installed in the black box and in a solar sunroof.

\section{B. Determining NMOT at black-box}

The goal of our test method is to replicate the temperatures that would be observed if a module were implemented into a car roof (or similar) configuration. Fig. 5 shows application of King's analysis for back-of-module temperatures measured for the modules mounted in the black box in the open and closed configurations ( $\mathrm{SC} 1$ and $\mathrm{SC} 2$ are large $\mathrm{cSi}, \mathrm{MC} 1$ and $\mathrm{MC} 2$ are small $\mathrm{mSi}$, and $\mathrm{GA} 1$ and $\mathrm{GA} 2$ are small GaAs modules, as described in [11]). The intercept and slope of the linear fit are the $a$ and $b$ coefficients (Eq. 4).
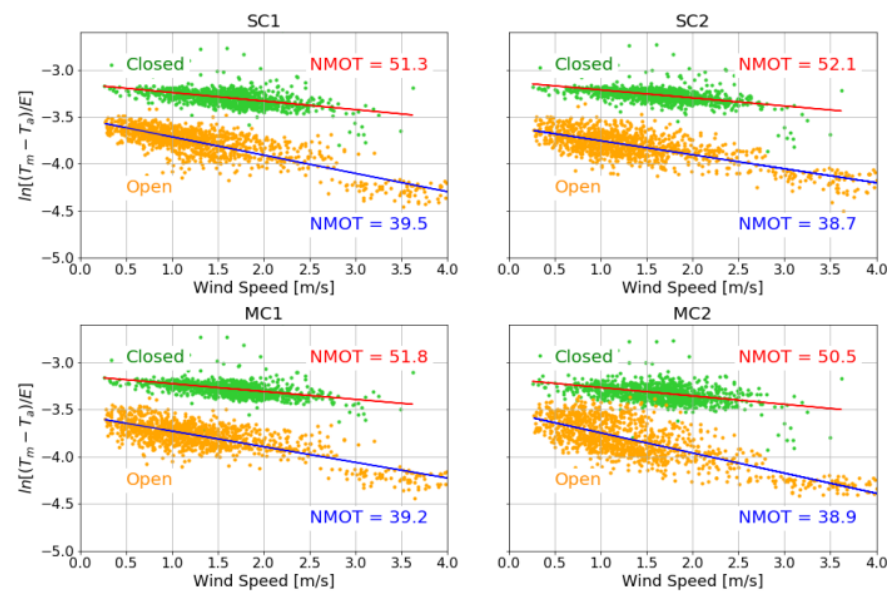

GA1
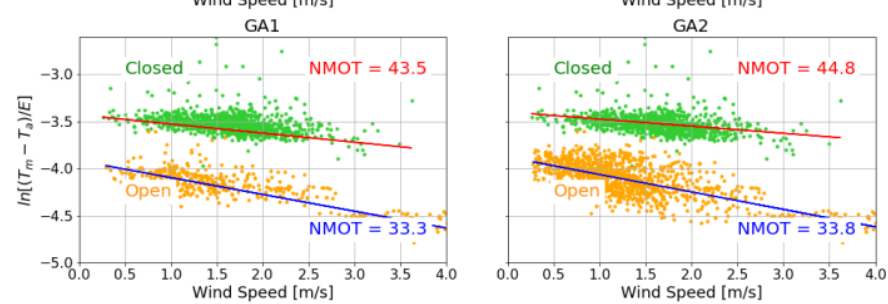

Fig. 5. Rise above ambient temperature for six modules mounted in the black box while its sides (see Fig. 3 images) were open (orange) and closed (green). The plots show King's approach [2] for determining operating temperature; the derived values are labeled for each line. Data were collected on May 1-13 for the closed configuration and June 7-11 for the open configuration.
A second approach for the NMOT determination is based on the temperature rise above ambient data, plotted as a function of irradiance as represented in Fig. 6 for the same modules and measurement conditions described for Fig. 5. The NMOT values calculated in Fig. 6 fall within $1^{\circ}-2^{\circ} \mathrm{C}$ of those calculated for Fig. 5. The nominal NMOT values (determined as the nameplate NOCT minus $6^{\circ} \mathrm{C}$ as discussed above) are plotted as black dots when available (only provided in $\mathrm{SC} 1$ and MC2 datasheets).
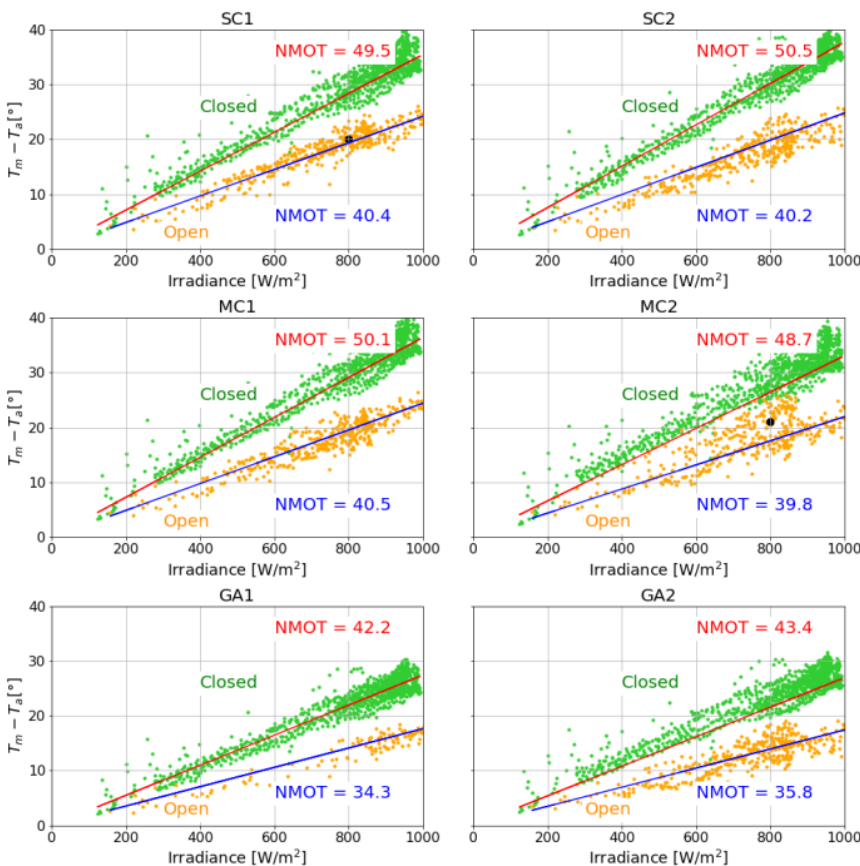

Fig. 6. Module temperature $\left(T_{m}\right)$ rise above ambient temperature $\left(T_{a}\right)$ for the same periods as in Fig. 5. Data are plotted using the approach of Eq. 1 with a fixed wind speed close to $1 \mathrm{~m} / \mathrm{s}$ (wind filter: $0.75 \mathrm{~m} / \mathrm{s}$ $<\mathrm{w}<1.25 \mathrm{~m} / \mathrm{s}$ ). The resulting NMOT values are indicated for each line.

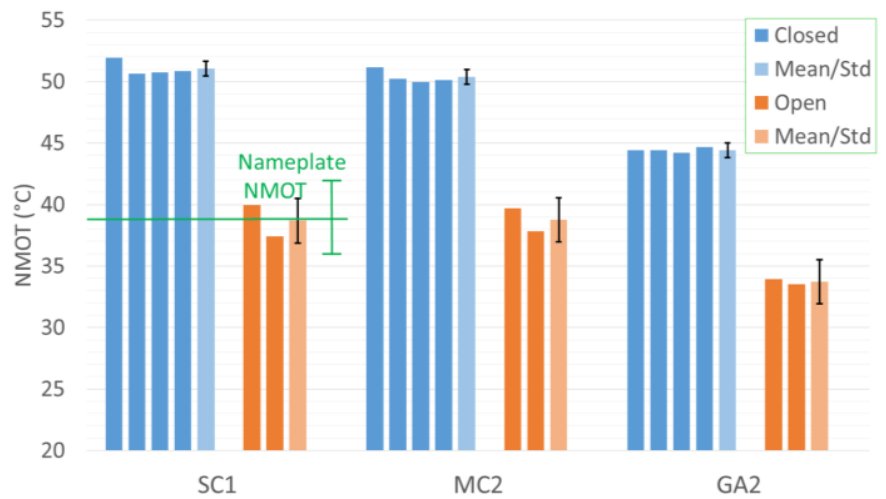

Fig. 7. Comparison of NMOT values (following King's method) measured for two Si modules and one GaAs module measured in black box with open and closed configuration. Measuring periods of at least 4 sunny days, from March to June. 
The NMOT values obtained during different times of sunny weather are compared in Fig. 7. The NMOT determination at different periods and conditions for the closed box is very consistent. The worst case for the six modules provided a standard deviation sdt $=0.59{ }^{\circ} \mathrm{C}$ for the closed box. In contrast, the open box shows higher variability (worst case $\operatorname{std}=1.8^{\circ} \mathrm{C}$ ), mainly due to a windy measuring period in March. This effect must be further studied to determine the filter requirements for the operating conditions for the open box, as well as a side-byside comparison to open-rack modules.

\section{CONCLUSIONS}

The black box used in this study is observed to heat up in the sun to a temperature that is similar to a module deployed in a sun roof of a car, as one example of a use environment. It appears to provide a uniform environment for testing modules when it is in the closed configuration, giving consistent results in different time periods. The black box can also give variable conditions by opening/closing the sides and/or adding insulation providing a tool to test a range of configurations. Two methods of analyzing the data were shown to give consistent NMOT values (within $2{ }^{\circ} \mathrm{C}$ ). A comparison of silicon and gallium arsenide modules showed that the gallium arsenide modules operate at $\sim 76 \%$ increased temperature relative to the temperature increase above ambient observed for the silicon modules.

\section{REFERENCES}

[1] Y. Ota, T. Masuda, K. Araki, M. Yamaguchi, "A mobile multipyranometer array for the assessment of solar irradiance incident on a photovoltaic-powered vehicle", Solar Energy, vol 184, 2019, p. 84-90.

[2] D. L. King, et al, PV Array Performance Model Report: SAND2004e3535. Sandia National Laboratories, 2004.

[3] E. Skoplaki, J. Palyvos, "On the temperature dependence of photovoltaic module electrical performance: A review of efficiency/power correlations", Solar Energy, vol 83, no. 5, 2009, p. 614-624.

[4] J. Oh, et al, "Temperatures of BAPV," Proc. SPIE 7773, Reliability of PV Cells, Modules, Components, and Sys III, p. 05, 2010.

[5] M.W. Davis, et al, "Prediction of BIPV cell temperatures," Transactions ASME, J. Solar Energy Eng., B, pp. 200-210, 2001.

[6] International Electrotechnical Commission, International Standard IEC 61853 current draft under discussion.

[7] International Electrotechnical Commission, International Standard IEC 61215-1-1:2005.

[8] M. Muller et al, "Evaluating the IEC 61215 NMOT Procedure Against the Existing NOCT Procedure with PV Modules in a Side-by-Side Configuration", 38th IEEE PVSC, 2012, p. 697.

[9] International Electrotechnical Commission, International Standard IEC 61215-1-1:2016

[10] ASTM G7 / G7M-13, Standard Practice for Atmospheric Environmental Exposure Testing of Nonmetallic Materials, ASTM International, West Conshohocken, PA, 2013

11] A. Wheeler, M. Leveille, I. Anton, M. Limpinsel, S. Kurtz, "Outdoor Performance of PV Technologies in Simulated Automotive Environments", 46th IEEE PVSC, 2019.

[12] M. Koehl, et al, "Modeling of the NOCT based on outdoor weathering," Sol. Energy Mat. and Solar Cells, 95 p. 1638, 2011. 